\title{
Age: The Most Important Risk Factor for Cervical Stenosis and Cervical Intraepithelial Neoplasia Recurrence After Cervical Conization
}

Chihiro Kanamine, Yuko Shimoji, Tadaharu Nakasone, Yoshihisa Arakaki, Yusuke Taira, Tomoko Nakamoto, Takuma Ooyama, Tadatsugu Kinjo, Keiko Mekaru, Wataru Kudaka, Hitoshi Masamoto and Yoichi Aoki*

Department of Obstetrics and Gynecology, University of the Ryukyus, Japan

Submission: November 01, 2018; Published: November 15, 2018

*Corresponding author: Yoichi Aoki, Department of Obstetrics and Gynecology, Graduate School of Medicine, University of the Ryukyus, 207 Uehara Nishihara, Okinawa 903-0215, Japan

\begin{abstract}
Background: To evaluate the incidence of cervical stenosis and rate of recurrence after laser conization and to identify risk factors for these conditions.

Methods: Data on 370 patients with CIN3, or AIS treated with only laser conization between 2010 and 2016 at our Hospital were collected. Multivariate analyses were used to evaluate associations between clinical variables and postoperative cervical stenosis or CIN recurrence.

Results: The median age was 43 (range, 27-89) years and follow-up period was 27 (range, 1-103) months. Cervical stenosis was diagnosed in 37 patients (10.0\%), with CIN recurrence in 21 patients (5.7\%). The multivariate analysis identified age ( $\geq 44$ years) and parity as significant risk factors for cervical stenosis and revealed that positive surgical margins, smoking, and age ( $\geq 44$ years) were significant risk factors for CIN recurrence. Only patient age ( $\geq 44$ years) was a significant risk factor for both cervical stenosis and CIN recurrence. Furthermore, patients aged $\geq 44$ years and with positive surgical margins exhibited a significantly higher rate of CIN recurrence and significantly shorter CIN-free period than those with negative surgical margins.
\end{abstract}

Conclusion: Other surgical options such as subsequent hysterectomy may be considered and can be beneficial for such elderly patients. Keywords: Cervical conization; Cervical stenosis; CIN; Recurrence

Abbreviatations: MIC: Microinvasive Carcinoma; CIN: Cervical Intraepithelial Neoplasm; AIS: Adenocarcinoma in Situ; LEGH: Lobular Endocervical Glandular Hyperplasia;SCJ:Squamo-Columnar Junction; OR: Odds Ratio; CI: Confidence Interval; HR: Hazard Ratio; CI: Confidence Interval

\section{Introduction}

Cervical conization is the gold standard for treating cervical precancerous lesions, even in elderly patients who no longer desire fertility preservation [1].Cervical stenosis,a complication of conization, can occasionally lead toan unsatisfactory followup and post-conization unsatisfactory cytology or colposcopy. Reportedly, the frequency of cervical stenosis after loop excision and conization ranges from 5.4\%-16.8\% [2-6]. Moreover, the rate of recurrence after conization is approximately $6.6 \%$ [1]. Additionally, patients who were previously treated for cervical intraepithelial neoplasia (CIN) were observed to have an increased risk of cervical cancer[7], and the long-term risk of invasive cancer remained higher among women who were treated for CIN[8]. Cervical stenosis and unsatisfactory cytology or colposcopy are the significant factors preventing accurate cytology and colposcopy follow-up without missing relapses. This study aimed to evaluate the incidence of cervical stenosis and rate of recurrence after laser cone biopsy and to identify risk factors for these conditions.

\section{Patients and Methods}

Data on 370 patients with CIN3, adenocarcinoma in situ (AIS), or atypical glandular cells treated with only laser conization between 2010 and 2016 at the University of the Ryukyus Hospital were collected. The patients' clinicopathological data 
were reviewed from patient charts. This retrospective study was approved by the Institutional Review Board of our university (\#1297) on June 6, 2018.

All patients were preoperatively diagnosed using cervical cytology, colposcopy, and directed biopsy. All patients underwent the same surgical protocol: $\mathrm{CO}_{2}$ laser conizationusing a $40-\mathrm{W}$ beam power and a $0.5-\mathrm{mm}$ width spot. A Nelaton catheter (8Fr.) was retained in the cervical canal for 7 days after the procedure. The diameters of the excised cone samples were measured, and the samples were then pathologically diagnosed. Follow-up examinations were performed every alternate month for the first year and every 3-6 months thereafter. Cytological sampling was conductedat the same visit. Cervical stenosis wasdefined as cervical os narrowing, which prevented the insertion of acytobrush. Recurrence was defined as a histologically confirmed CIN2 or worse.

All statistical analyses were performed using JMP software version 10.0 (SAS Institute, Cary, NC, USA).Fischer's exact test wasused for analyzing categorical data. Multivariate analyses were used to evaluate associationsbetween clinical variables and postoperative cervicalstenosis or CIN recurrence. For multivariate analyses, a logistic regression model for cervical stenosis and a Cox proportional hazard model for CIN recurrence were used to identify variables with independent effects. CIN recurrence-free curves were estimated using the Kaplan-Meier method, and differences were assessed using the log-rank test. A p-value less than 0.05 was considered statistically significant.

Result

The enrolled patients had a median age of 43 (range, 2789) years. The median follow-up period was 27 (range, 1-103) months. The pathological diagnoses of patients are shown in Table 1. Most of the patients (68.4\%) were diagnosed with CIN3 or AIS. The median excised cone height was 11 (range, 2-30) $\mathrm{mm}$. Additionally, surgical margins could be assessed in all patients. Pathological diagnoses revealed that CIN was involved in endocervical and vaginal surgical margins of 51(13.8\%) and 13 patients (3.5\%), respectively.
Table 1: Patient characteristics $(\mathrm{N}=370)$

\begin{tabular}{|c|c|c|}
\hline \multicolumn{3}{|c|}{ Variables } \\
\hline \multicolumn{2}{|c|}{ Age (years), median (range) } & $43(27-89)$ \\
\hline \multicolumn{2}{|c|}{ Follow up period, months (range) } & $27(1-103)$ \\
\hline \multirow{6}{*}{$\begin{array}{l}\text { Pathological } \\
\text { diagnosis }\end{array}$} & MIC (FIGO stage IA1) & $23(6.2)$ \\
\hline & CIN3, AIS & $253(68.4)$ \\
\hline & CIN2 & $65(17.6)$ \\
\hline & CIN1 & $17(4.6)$ \\
\hline & LEGH & $4(1.1)$ \\
\hline & Others & $82.1)$ \\
\hline \multicolumn{2}{|c|}{ Cone height (mm), median (range) } & $11(2-30)$ \\
\hline \multirow{3}{*}{$\begin{array}{l}\text { Surgical margin } \\
\text { positive (\%) }\end{array}$} & & $64(17.3)$ \\
\hline & Endocervical side & $51(13.8)$ \\
\hline & Vaginal side & $13(3.5)$ \\
\hline \multicolumn{2}{|c|}{ Nulliparity (\%) } & $100(27.0)$ \\
\hline \multicolumn{2}{|c|}{ Smoker (\%) } & $109(29.5)$ \\
\hline \multicolumn{2}{|c|}{ Recurrence (\%) } & $21(5.7)$ \\
\hline \multicolumn{2}{|c|}{ Cervical stenosis (\%) } & $37(10.0)$ \\
\hline
\end{tabular}

MIC; microinvasive carcinoma, CIN; cervical intraepithelial neoplasm, AIS; adenocarcinoma in situ, LEGH; lobular endocervical glandular hyperplasia, SCJ; squamo-columnar junction

Cervical stenosis was diagnosed in 37 patients (10.0\%), with CIN recurrence in 21 patients (5.7\%). The univariate analysis demonstrated that patient age, parity, and smoking were significant risk factors, and the multivariate analysis identified age ( $\geq 44$ years) [odds ratio (OR), 21.31; 95\% confidence interval (CI), 6.255-133.4; $\mathrm{p}<0.0001$ ] and parity (OR, 3.209; 95\% CI, 1.048-14.02; $\mathrm{p}=0.0403$ ) as significant risk factors for cervical stenosis (Table 2). The Cox proportional hazard model revealed that positive surgical margins [hazard ratio (HR), 13.83; 95\% CI, 5.477-39.46; $\mathrm{p}<0.0001$ ], smoking (HR, 3.945;95\% CI, 1.54510.35 ; $\mathrm{p}=0.0044$ ), and age ( $\geq 44$ years) (HR, $2.770 ; 95 \% \mathrm{CI}, 1.058$ $7.819 ; \mathrm{p}=0.0380$ ) were significant risk factors for CIN recurrence (Table 3). After CIN recurrence, six patients underwent reconization, seven underwent hysterectomy, and eight were closely followed-up.

Table 2: Risk factors for cervical stenosis after conization

\begin{tabular}{|c|c|c|c|c|c|c|}
\hline & & \multicolumn{2}{|c|}{ Univariate Analysis (Fisher's Exact Test) } & \multicolumn{3}{|c|}{ Multivariate Analysis (Logistic Regression Model) } \\
\hline & & Cervical stenosis / n (\%) & $P$ value & OR & $95 \% \mathrm{CI}$ & P value \\
\hline \multirow{2}{*}{ Age (years) } & $\geq 44$ & $35 / 167(21.0 \%)$ & $<0.0001$ & 21.31 & $6.255-133.4$ & $<0.0001$ \\
\hline & $<44$ & $2 / 203(1.0 \%)$ & & & & \\
\hline \multirow{2}{*}{ Parity } & Yes & $34 / 270(12.6 \%)$ & 0.0024 & 3.209 & $1.048-14.02$ & 0.0403 \\
\hline & No & $3 / 100(3.0 \%)$ & & & & \\
\hline \multirow{3}{*}{ Smoker } & Yes & $5 / 109(4.6 \%)$ & 0.0126 & 2.41 & $0.926-7.594$ & 0.0728 \\
\hline & No & $32 / 253(12.6 \%)$ & & & & \\
\hline & unknown & $0 / 8$ & & & & \\
\hline \multirow{2}{*}{ Cone height (mm) } & $\geq 12$ & $23 / 183(12.6 \%)$ & 0.1017 & 0.791 & $0.361-1.694$ & 0.5474 \\
\hline & $<12$ & 14/187 (7.5\%) & & & & \\
\hline
\end{tabular}


Journal of Gynecology and Women's Health

\begin{tabular}{|c|c|c|c|c|c|c|}
\hline \multirow{2}{*}{ Surgical margin } & Positive & $6 / 65(9.2 \%)$ & 0.8556 & 1.183 & $0.459-3.477$ & 0.7388 \\
\cline { 2 - 7 } & Negative & $31 / 305(10.2 \%)$ & & & \\
\hline
\end{tabular}

OR; odds ratio, $\mathrm{Cl}$; confidence interval

Table 3: Risk factors for $\mathrm{CIN}$ recurrence $(\mathrm{N}=370)$

\begin{tabular}{|c|c|c|c|c|c|c|}
\hline & & \multicolumn{2}{|c|}{ Univariate Analysis (Log-Rank Test) } & \multicolumn{3}{|c|}{ Multivariate Analysis (Cox Proportional Hazard Model) } \\
\hline & & Recurrence / n(\%) & $P$ value & HR & $95 \% \mathrm{CI}$ & $P$ value \\
\hline \multirow[t]{2}{*}{ Age (years) } & $\geq 44$ & $14 / 167(8.4 \%)$ & 0.1096 & 2.77 & $1.058-$ & 0.038 \\
\hline & $<44$ & $7 / 203(3.4 \%)$ & & & 7.819 & \\
\hline \multirow[t]{2}{*}{ Parous } & Yes & $16 / 270(5.9 \%)$ & 0.9511 & 1.134 & $0.360-$ & 0.8144 \\
\hline & No & $5 / 100(5.0 \%)$ & & & 3.026 & \\
\hline \multirow[t]{3}{*}{ Smoker } & Yes & $11 / 109(10.1 \%)$ & 0.0104 & 3.945 & $1.545-$ & 0.0044 \\
\hline & No & $10 / 253(4.0 \%)$ & & & 10.35 & \\
\hline & unknown & $0 / 8$ & & & & \\
\hline \multirow[t]{2}{*}{ Cone height (mm) } & $\geq 12$ & $13 / 183(7.1 \%)$ & 0.358 & 1.595 & $0.653-$ & 0.308 \\
\hline & $<12$ & $8 / 187$ (4.3\%) & & & 4.142 & \\
\hline \multirow[t]{2}{*}{ Surgical margin } & Positive & $14 / 65(21.5 \%)$ & $<0.0001$ & 13.83 & $5.477-$ & $<0.000$ \\
\hline & Negative & $7 / 305(2.3 \%)$ & & & 39.46 & 1 \\
\hline
\end{tabular}

In our study, only patient age ( $\geq 44$ years) was a significant risk factor for both cervical stenosis and CIN recurrence. Eight of 29 patients $(27.6 \%)$ who were $\geq 44$ years and had positive surgical margins had CIN recurrence; the Kaplan-Meier curve of the CIN-free period of these patients was significantly shorter than that of patients with negative surgical margins (log-rank test, $\mathrm{p}<0.0001$ ) (Figure 1).

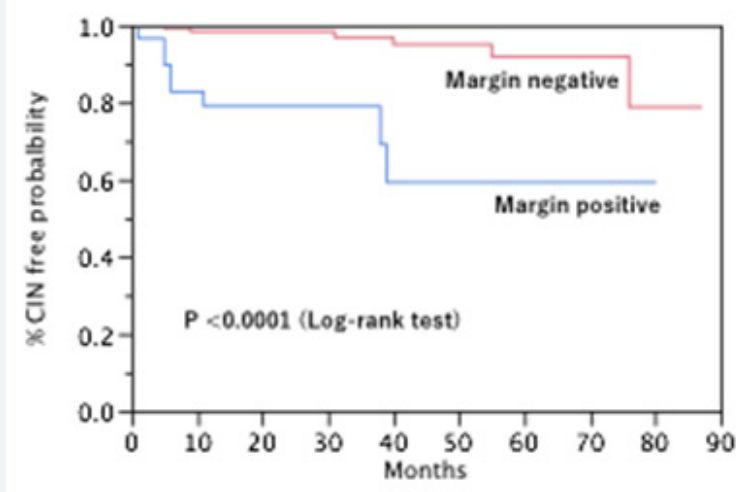

Figure 1: Eight of 29 patients $(27.6 \%)$ aged $\geq 44$ years and with positive surgical margins exhibited CIN recurrence; the KaplanMeier curve of the CIN-free period was significantly shorter than that of patients with negative surgical margins (log-rank test, $p$ $<0.0001)$.

\section{Discussion}

In our study, 35 of 167 patients (21.0\%) who were $\geq 44$ years had cervical stenosis after laser conization, which occurred at a significantly higher rate than that in younger patients (2 of 203 patients, 1.0\%). The multivariate analysis revealed that laser conization was a highly significant risk factor for cervical stenosis. Reportedly, old age is a risk factor for cervical stenosis.
Houlard et al. demonstrated that age was the only significant independent predictor of cervical stenosis, as identified in 40 of 375 patients treated with laser cone biopsy [4]. Penna et al. [5] stressed that the rate of cervical stenosis was higher in postmenopausal patients, leading to an unsatisfactory follow-up. Furthermore, a report from Japan showed that in a retrospective analysis of 522 cases, elderly patients ( $\geq 46$ years) were at a higher risk of cervical stenosis and CIN recurrence [6]. Formerly, the volume of removed tissue and excision height were the primary factors associated with cervical stenosis [2,3]. However, recent publications show that patient age is a much stronger risk factor for cervical stenosis [4-6] because many elderly patients were treated with conization in recent studies, as in our study.

The surgical margin status represented the most important predictor for CIN recurrence after conization $[1,9,10]$. In our study, positive surgical margins were the most important risk factor for CIN recurrence after conization, which is consistent with previous reports. Furthermore, recent reports demonstrated that patient age was associated with a high risk of CIN recurrence [5,6]. These recent reports stressed the existence of a significantly higher association between cervical stenosis and CIN recurrence in elderly patients than that in young patients, which was consistent with our results.

In our study, only patient age ( $\geq 44$ years) was a significant risk factor for both cervical stenosis and CIN recurrence. Furthermore, patients aged $\geq 44$ years and with positive surgical margins exhibited a significantly higher rate of CIN recurrence and significantly shorter CIN-free period than those with negative surgical margins. Other surgical options such as subsequent hysterectomymay be considered and can be beneficial for such elderly patients. 


\section{Acknowledgment}

The authors would like to thank Enago for the English language review of this article.

\section{Compliance with Ethical Standards}

Disclosure of potential conflicts of interest: The authors declare that there is no conflict of interest regarding the publication of this paper.

Research involving human participants and/or animals: All procedures performed in studies involving human participants were in accordance with the ethical standards of the institutional and/or national research committee and with the 1964 Helsinki declaration and its later amendments or comparable ethical standards. This retrospective study was approved by the Institutional Review Board of our university (\#1297) on June 6, 2018.

Informed consent: We used opt-out method to obtain consent from the patients.

\section{References}

1. Arbyn M, Redman CWE, Verdoodt F, Kyrgiou M, Tzafetas M, et al. (2017) Incomplete excision of cervical precancer as a predictor of treatment failure: a systematic review and meta-analysis. Lancet Oncol 18 (12) 1665-1679.

2. Baldauf JJ, Dreyfus M, Ritter J, Meyer P, Philippe E, et al. (1996) Risk of cervical stenosis after large loop excision or laser conization. Obstet Gynecol 88(6): 933-938.
3. Suh-Burgmann EJ, Whall-Strojwas D, Chang Y, Hundley D, Goodman A, et al. (2000) Risk factors for cervical stenosis after loop electrocautery excision procedure. Obstet Gynecol 96(5 Pt 1): 657-660.

4. Houlard S, Perrotin F, Fourquet F, Marret H, Lansac J, et al. (2002) Risk factors for cervical stenosis after laser cone biopsy. Eur J Obstet Gynecol Reprod Biol 104(2): 144-147.

5. Penna C, Fambrini M, Fallani MG, Pieralli A, Scarselli G, et al. (2005) Laser $\mathrm{CO}_{2}$ conization in postmenopausal age: risk of cervical stenosis and unsatisfactory follow-up. Gynecol Oncol 96(3): 771-775.

6. Tanaka Y, Ueda Y, Kakuda M, Kubota S, Matsuzaki S, et al. (2017) Predictors for recurrent/persistent high-grade intraepithelial lesions and cervical stenosis after therapeutic conization: a retrospective analysis of 522 cases. Int J Clin Oncol 22(5): 921-926.

7. Rebolj M, Helmerhorst T, Habbema D, Looman C, Boer R, et al. (2012) Risk of cervical cancer after completed post-treatment follow-up of cervical intraepithelial neoplasia: population based cohort study. BMJ 345: e6855.

8. Melnikow J, McGahan C, Sawaya GF, Ehlen T, Coldman A, et al. (2009) Cervical intraepithelial neoplasia outcomes after treatment: long-term follow-up from the British Columbia Cohort Study. J Natl Cancer Inst 101(10): 721-728.

9. Lu CH, Liu FS, Kuo CJ, Chang CC, Ho ES, et al. (2006) Prediction of persistence or recurrence after conization for cervical intraepithelial neoplasia III. Obstet Gynecol 107(4): 830-835.

10. Serati M, Siesto G, Carollo S, Formenti G, Riva C, et al. (2012) Risk factors for cervical intraepithelial neoplasia recurrence after conization: a 10year study. Eur J Obstet Gynecol Reprod Biol 165(1): 86-90.

\section{Your next submission with Juniper Publishers} will reach you the below assets

- Quality Editorial service

- Swift Peer Review

- Reprints availability

- E-prints Service

- Manuscript Podcast for convenient understanding

- Global attainment for your research

- Manuscript accessibility in different formats ( Pdf, E-pub, Full Text, Audio)

- Unceasing customer service

Track the below URL for one-step submission https://juniperpublishers.com/online-submission.php 